\title{
Regulation of EMT by KLF4 in Gastrointestinal Cancer
}

\author{
Jiujie Cui ${ }^{1,3}$, Min Shi $^{2,3}$, and Keping $\mathbf{X i e}^{3}$ \\ ${ }^{1}$ Department of Oncology, Shanghai Jiaotong University Affiliated First People's Hospital, \\ Shanghai, People's Republic of China \\ ${ }^{2}$ Department of Surgery, Shanghai Jiaotong University Affiliated Ruijin Hospital, Shanghai, \\ People's Republic of China \\ ${ }^{3}$ Gastroenterology, Hepatology \& Nutrition, The University of Texas MD Anderson Cancer Center, \\ Houston, Texas
}

\section{Abstract}

Gastrointestinal (GI) cancer is characterized by its aggressiveness, but the underlying mechanism is not fully understood. Studies reveal that epithelial to mesenchymal transition (EMT), which is regulated by a series of transcription factors and signaling pathways, is strongly associated with GI cancer cell proliferation, invasion and metastasis. In essential, EMT is a product of crosstalk between signaling pathways. Krüppel-like factor 4 (KLF4), a zinc finger-type transcription factor, is decreased or lost in most GI cancers. By transcriptional regulating its downstream target genes, KLF4 plays important roles of GI cancer tumorigenesis, proliferation and differentiation. In this review, we focus on the mechanism of KLF4 in GI cancer EMT, and demonstrate that through crosstalk with TGF- $\beta$, Notch, and Wnt signaling pathways, KLF4 negatively regulates EMT of GI cancers. Finally, we indicate the challenging new frontiers for KLF4 which contributes to better understanding of the mechanism of GI cancer aggressiveness.

\section{Keywords}

KLF4; gastrointestinal cancer; EMT; TGF- $\beta$; Notch; Wnt

\section{Introduction}

\begin{abstract}
Gastrointestinal (GI) cancer, which refers to the cancers generated from esophagus, stomach, intestine, gallbladder, liver and pancreas, is a leading cause of cancer-related mortality worldwide [1]. In the United States, estimated 284,680 new GI cancer cases and 142,510 deaths in 2012, and is responsible for about one third of the cancer burden [2]. For GI cancers, surgical resection is the only potentially curative therapy, but most of the patients are diagnosed at the late stage and lose the opportunities of curative resection due to highly aggressive nature of GI cancers. Therefore, a better understanding of the mechanism which contributes to GI cancer aggressiveness is urgently needed.
\end{abstract}

\footnotetext{
Address requests for reprints to: Keping Xie, Department of Gastroenterology, Hepatology \& Nutrition, Unit 955, The University of Texas MD Anderson Cancer Center, 1515 Holcombe Boulevard, Houston, Texas 77030. phone: 713-794-5073; fax: 713-745-3654; kepxie@mdanderson.org.
} 
Multiple lines of evidence have demonstrated the importance of epithelial to mesenchymal transition (EMT), a process of the transformation of epithelial cells to a mesenchymal phenotype and lose their cell-cell contacts, in GI cancer cells aggressiveness. In the 1980s, EMT was first described and later cancer researchers discovered that it was strongly associated with cancer cell proliferation, invasion and metastasis [3, 4]. The aggressive nature of cancer is associated to the abnormalities of a series molecular, including activation of tumor oncogenes, inactivation of tumor suppressor genes, reactivation of telomerase, and overexpression of growth factors and their receptors. Thereafter, effects of various genes, factors and molecular pathways which were identified as important mechanism of cancer development and progression have been extensively studied on EMT of GI cancer.

Krüppel-like factor 4 (KLF4), belonging to Krüppel-like factor family, is a zinc finger-type transcription factor highly expressed in various human tissues, including differentiated, postmitotic epithelial cells of the gastrointestinal tract. Several lines of evidence have revealed that KLF4 acts as tumor suppressor in GI cancer, and it negatively regulates cell proliferation and promotes tissue differentiation, and loss of KLF4 expression is a predictor of poor survival [5]. Recent studies indicated that KLF4 was a key negative regulator of EMT and its expression was reduced during the EMT process [6]. This review will summarize what is known about KLF4 in GI cancer development and progression, and the role of KLF4 in regulating EMT, so as to get a better understanding of the mechanism that contributes to GI cancer aggressiveness.

\section{EMT}

EMT was discovered 30 years ago because of its critical roles in embryonic development, and in 1990s, cancer researchers found that EMT was strongly associated with tumor cell proliferation, invasion and metastasis [3, 4, 7]. It is a process typically characterized by epithelial cells losing cell-cell adhesions and apical-basal polarity, undergoing a remodeling of the cytoskeleton and developing a fibroblastoid motile phenotype, which activates the expression of a series of genes. By suppressing the expression of junctional complexes, such as E-cadherin, adenovirus receptor (CAR), Zona occludin-1 (ZO-1), occluding, claudin-1 and claudin-7, cells lose the cell-cell contacts and detach from each other, and by increasing the expression of mesenchymal markers, such as N-cadherin, vimentin, S100A4, a-smooth muscle actin, and extracellular matrix components, such as collagens 1 and 2, cells acquire the ability to migrate and invade the extracellular metrices $[8,9]$.

In cancer cells, essential step of EMT is the downregulation of E-cadherin which binds with its extracellular domain to another E-cadherin of the neighboring epithelial cells, and therefore disassembles the cell-cell contacts $[10,11]$. It is well known that downregulation of E-cadherin is associated with the invasive and undifferentiated phenotype in many GI cancers, including esophageal cancer, gastric cancer, colorectal cancer, gallbladder cancer, liver cancer and pancreatic cancer [12-17]. Another adhesion molecule N-cadherin, which is typically expressed on mesenchymal cell surface, is correlated with the motility and invasive potential of cancer cells [18]. In our previous studies, we found that reduced E-cadherin expression and upregulated $\mathrm{N}$-cadherin expression were associated with the EMT, invasion and metastasis potentials of pancreatic cancer cells [19]. In fact, multiple lines of researches 
have revealed that the cadherin-switch from E-cadherin to $\mathrm{N}$-cadherin has critical function in cancer progression and is essential for increased motility and migration [20].

E-cadherin can be transcriptionally repressed by a number of transcription factors, such as ZEB (ZEB1 and ZEB2), the Snail (Snail1 and Snail2) and Twist [21]. These transcription factors are downstream of signaling pathways, including transforming growth factor- $\beta$ (TGF- $\beta$ ), Wnt/ $\beta$-catenin, Notch, fibroblast growth factor (FGF), signal transducer and activator of transcription-3 (STAT-3), epidermal growth factor (EGF) and nuclear factor (NF)- $\kappa \mathrm{B}[20,22]$. Loss expression of E-cadherin leads to the release of its intracellular partner $\beta$-catenin which thereafter translocates into the nucleus and transcriptionally modulates a number of genes, such as cyclin D1, CD44, c-Myc, and vascular endothelial growth factor (VEGF), and promotes cancer development and progression [22]. Besides canonical Wnt signaling pathway, disassembly of the E-cadherin adhesion complex can also lead to the displacement of $\mathrm{p} 120$, which represses the small $\mathrm{G}$ protein RhoA and results in the activation of Cdc42 and Rac1 [20]. They together reorganize the actin cytoskeleton and promote the migration of cancer cells [23]. Therefore, the cadherin switch plays critical roles in EMT not only by changing the component of the cell-cell adhesion, but also by regulating various signaling pathways.

\section{The Suppressor Role of KLF4 in GI Cancer}

\subsection{Krüppel-like factor family and KLF4}

Krüppel-like factors (KLFs), which contain three $\mathrm{C} 2 \mathrm{H} 2$-type zinc fingers at the C-terminal and transactivation domain at the $\mathrm{N}$-terminal, are members of zinc-finger-containing transcription factors [24]. By binding to GC-rich or CACCC promoters with its co-activator p300/CBP, KLFs regulate the expression of a series of genes which play key roles in many biological processes, including cell proliferation, differentiation and stem cells reprogramming [25]. Till now, at least 17 members of KLFs have been identified in humans, and Klf4 was first cloned by two groups in 1996, and named gut-enriched Krüppel-like factor and epithelial zinc finger independently [26-28].

The gene of Klf4 has five exons and encodes a protein with 470 amino acids. Several functional domains have been identified in KLF4, including transcriptional activation and repression domains at N-terminus, DNA binding domain, and nuclear localization signal domain [29]. As a member of KLFs family, KLF4 binds to the CACCC element to regulate gene expression, yet KLF4 can also bind to other DNA sequences. The basic transcription element (BTE), which is often found in the promoter of a series highly conserved genes, is a high-affinity binding site of KLF4 [30,31]. With both transcriptionally active and repressive domains, KLF4 alters positive and negative regulation of its downstream target genes. Recent studies showed that the expression of KLF4 was decreased or lost in most GI cancers, including esophageal cancer, gastric cancer, colon cancer and liver cancer and by transcriptionally regulating its target gene, KLF4 played essential roles in GI cancer tumorigensis, cell proliferation and differentiation (Fig. 1) [32-40]. 


\subsection{Roles of KLF4 in GI cancer tumorigenesis}

Klf4 is one of a few genes which are proved to be downregulated in GI tumor early initiation. KLF4 is progressively lost as the tumor formation and progression. For example, in our previous studies, gastric cancer presented a significantly progressive loss of KLF4 expression as the stage advanced from I to IV [35]. Also, most human gastric cancer cell lines exhibited lost or decreased KLF4 expression at both mRNA and protein levels. In colon cancer development, KLF4 expression was significantly decreased in colonic adenomas as compared with adjacent normal mucosa [41, 42]. In a colon cancer tissue microarray, the expression of KLF4 was significantly decreased or lost in cancer tissues as compared with noncancer tissues and KLF4 was an independent predictor of survival [39]. Furthermore, Choi et al found that KLF4 was expressed in normal colonic mucosa and loss of KLF4 expression was observed in about a quarter of the colon cancers [38]. Decreased expression of KLF4 has also been found in esophageal cancer cell lines and tissues [32-34]. Besides these clinical evidence, by an established system in RKO colon cancer cells, which had an inducible promoter of Klf4, Dang et al demonstrated that overexpression of KLF4 reduced colony formation, in vivo tumrigenecity, and cell migration and invasion [43].

The tumor suppressor role of KLF4 in GI cancer is heightened by the fact that KLF4 is downregulated in the mouse models of gastrointestinal tumorigenesis. For example, in our previous studies, disruption of Klf4 in villin-positive antral mucosa cells (Villin$\mathrm{Cre}(+) ; K l f 4(\mathrm{fl} / \mathrm{fl})$ mice) significantly increased the incidence of gastric tumors [44]. Further studies revealed that KLF4 suppressed the transcription of FOXM1, an important oncogenic transcription factor which were essential for tumor initiation and progression [45, 46]. In another study, Katz et al generated gastric epithelia-specific Klf4 ablation mouse models and found that Klf4 mutant mice presented with increased proliferation and altered differentiation in the gastric epithelia, and they further demonstrated that $p 21^{W A F 1 / C I P 1}$ was an in vivo target of Klf4 [47]. In colon, Klf4-/- mice presented with a $90 \%$ decrease in the number of goblet cells, and KLF4 was required for the terminal differentiation of the goblet cells [48]. The ApcMin/+ mice was an excellent model for studying intestinal tumorigenesis. As compared with the ApcMin/+ mice, Klf4+/-/ApcMin/+ mice developed, on average, $50 \%$ more intestinal adenomas. Further RT-PCR experiments showed an inverse correlation between KLF4 mRNA levels and adenoma size in both $\mathrm{Klf4}(+/-) / A p c(\mathrm{Min} /+)$ and $\operatorname{Apc}(\mathrm{Min} /+)$ mice [49].

All these clinical and experimental findings suggest a tumor suppressor role of KLF4 in GI cancer, and decreased or lost expression of KLF4 contributes to the GI cancer tumorigenesis. But the molecular basis of the KLF4 inactivation in GI cancer is not fully demonstrated. Some studies may give us a few clues. Elevated microRNA-10b directly repressed the expression of KLF4 in esophageal cancer [50]. In gastric cancer, we provided evidence that promoter hypermethylation and hemizygous deletion contributed to the low levels of KLF4 [35]. In colon cancer, Dang et al demonstrated that KLF4 was induced upon the activation of the adenomatous polyposis coli (APC) gene but not the DNA methylation [37]. Their further studies revealed that the decreased expression of KLF4 was the result of mutation of the putative tumor suppressor homeodomain protein, CDX2 [51]. In another study, Zhao et al provided evidence that the $5^{\prime}$-untranslated region of KLF4 was 
hypermethylated in colon cancer [52]. Furthermore, KLF4 is a direct target of ubiquitinproteasome pathway [53]. These findings can't fully reveal the mechanism of the KLF4 inactivation in GI cancer, and some even conflict with each other, so further detailed studies should be carried out.

\subsection{Roles of KLF4 in GI cancer proliferation}

The involvement of KLF4 in GI cancer tumorigenesis is largely dues to its essential roles in repressing cancer cell cycle, promoting apoptosis, and inhibiting proliferation. KLF4 has been reported to be overexpressed in growth-arrested cells and is rare detected in proliferation cells [27]. Decreased expression of KLF4 in esophageal cancer cells results in increased proliferation and decreased adhesion ability [34]. Overexpression of KLF4 activates DNA repair pathway and represses esophageal carcinogenesis through suppressing proliferation and inducing cell apoptosis [32]. Furthermore, KLF4 transcriptionally represses the expression of survivin, interferon induced transmembrane protein 3 (IFITM3), and B lymphoma Mo-MLV insertion region 1 (Bmi1), which play important roles in cancer development and progression, and results in significant decrease of cancer cell proliferation and increase of apoptosis [54-56].

KLF4 is a critical regulator for cell cycle, and cells with overexpressed KLF4 will arrest at G1/S checkpoint [57-59]. Cell cycle is controlled by cyclin-dependent kinases (CDKs) whose activity is regulated by activators (cyclins) and inhibitors (CKIs) [60]. Regulation of these CDKs, and their activators and inhibitors is the first indication of KLF4 contributing to cancer cell cycle. Constitutive expression of KLF4 transactivates the expression of p21, p27 and p53, which are the main CKI proteins, and inhibits the synthesis of DNA [27, 41, 52, 61-63]. In mouse models, Katz et al found that Klf4 mutant mice showed increased proliferation and altered differentiation of the gastric epithelia, and $p 21^{W A F 1 / C I P 1}$ was an in vivo target of KLF4 [47]. Our group identified 4 KLF4 isoforms in human pancreatic cancer cells, and KLF4a, which primarily localized to the cytoplasm, reduced the expression of KLF4 classical target genes $p 27^{K i p}$ and $p 21^{\text {WAF1/CIP1 }}$, and promoted cell cycle progression and tumor formation of pancreatic cancer [64]. Further studies revealed that enforced expression of KLF4 led to significant cytoplasmic distribution of KLF4 protein and repressed the transcriptional effect of KLF4 on $p 27^{K i p}$ gene. In another study, the authors demonstrated that KLF4 was an essential mediator of p53-dependent G1/S cell cycle arrest following DNA damage [57, 58]. Besides transactivating several CKIs, KLF4 also represses the expression of positive cell cycle regulators. By competitive binding Sp1-binding sites on cyclinD1 promoter, KLF4 suppresses mRNA and protein level of cyclinD1 [65]. With the same mechanism, KLF4 repressed the expression and enzyme activity ornithine decarboxylase (ODC), and led to cell cycle arrest at the G1/S checkpoint [66]. Besides KLF4's essential role in G1/S checkpoint, in a DNA damage condition, KLF4 also played important roles in preventing centrosome amplification and maintaining the integrity of the G2/M checkpoint by transcriptionally repressing the cyclinB1 and cyclinE expression [59, 67].

All the above findings revealed an inhibitory role of KLF4 in GI cancer proliferation. In contrast with these studies, the expression of KLF4 was upregulated in other types of 
cancers, such as head and neck squamous cell cancer, breast cancer and oral squamous cancer, and functioned as an oncogene which enhanced tumor development and progression [68-70]. Apparently, Klf4 functioned as either a tumor suppressor gene or an oncogene, and had both negative and positive effects on cancer cell proliferation. Recent studies revealed that tumor suppressor or oncogenic function of KLF4 might dependent on the genetic background of the tumor type, especially the functional status of p21 [71]. Other factors or pathways, which contribute to switching between suppressor and oncogenic functions of KLF4 in cancer development and progression, should be further studied.

\subsection{Roles of KLF4 of GI cancer differentiation}

In addition to its well described role in GI cancer cell proliferation, KLF4 also has important regulating effect on differentiation. KLF4 was highly expressed in terminally differentiated layers of epidermis, and Klf4-/- mice died within 15 hours after birth because of the loss of skin barrier function and show disturbed late-stage differentiation of the epidermis [72]. In colon, Klf4 was a goblet cell-specific differentiation factor. Klf4-/- mice showed normal cell proliferation and death rates in colon, but had a $90 \%$ decrease in the number of goblet cells. By in situ hybridization, Klf4-/- mice exhibited abnormal expression of Muc2 which was the goblet cell-specific marker [48]. Therefore, KLF4 had an essential role in colonic epithelial cell differentiation. In gastric epithelia-specific Klf4 ablation mouse models, more than $50 \%$ decrease of mature zymogenic cells, but 4-fold increase in the number of TFF2/SP-positive mucue cells and 2-fold increase in the number of pit cells were found [47]. Besides mouse models, transcriptional profiling of KLF4 had showed that KLF4 regulated the expression of a series of epithelial-specific keratin [73]. Furthermore, in esophageal squamous epithelium, KLF4 transcriptionally upregulated the expression of differentiation genes Epstein-Barr virus ED-L2 and keratin 4, and meanwhile, in pancreatic ductal cells, KLF4 upregulated the expression of keratin 19 [74, 75].

Taken together, all the above studies reveal that KLF4 is critical in specific epithelial proliferation and differentiation. In GI cancers, KLF4 also functions as a promoter of cancer cell differentiation. For example, in esophageal cancer, overexpression of KLF4 transcriptionally elevated the expression of small proline-rich protein 1A (SPRR1A), small proline-rich protein 2A (SPRR2A) and keratin 4 (KRT4), which were squamous cell differentiation associated genes, and resulted in squamous cell differentiation [34]. In colon cancer cell lines, the expression level of KLF4 was increasing during the differentiation induced by butyrate, which was an inhibitor of histone deacetylases (HDAC) and an inducer of differentiation. KLF4 transcriptionally activated the expression of intestinal alkaline phosphatase (IAP), which was an enterocyte differentiation marker [76, 77].

The role of KLF4 in differentiation has been described for a long time, but recent studies of the induced pluripotent stem cells (iPS) have identified KLF4 as one of the four transcription factors which reprogram somatic cells into iPS through combination [78]. Furthermore, in cancer stem cells, Leng Z et al provided evidence that KLF4 was overexpressed only in spheroid cells and knockdown KLF4 in cancer stem cells led to significant decrease of cancer stem cell markers, resistance to chemicals, invasion, migration, and tumorigenesis both in vitro and in vivo [79]. These studies reveal another role 
of KLF4 in regulating dedifferentiation, which is inconsistent with previous studies, so further studies are still needed.

\section{Roles of KLF4 in Regulating GI Cancer EMT}

Over the past decades it has been demonstrated that EMT is a multistage process, during which dramatic changes in cell morphology and biology accompanied with substantial changes in gene expression profile take place. Ever-increasing evidences have revealed that a number of transcription factors play critical role in the initiation and execution of EMT, including Snail1 (Snail), Snail2 (Slug), ZEB1, ZEB2 (Sip1), Twist1, FoxC2, E47, KLF8, goosecoid, Sox9, NF- $\kappa$ B et al [80]. Recently, KLF4 has been suggested to function as a transcriptional activator of epithelial genes and as a suppressor of mesenchymal genes during the process of EMT [81-84]. In hepatocellular carcinoma, exogenous KLF4 expression repressed mesenchymal characteristics, and changed the cell morphology to a more epithelial phenotype, and then restrained cell migration and invasion activities, as well as tumor growth and lung colonization, whereas KLF4 knockdown enhanced mesenchymal features and cell migration. Further mechanism research demonstrated that KLF4 was able to bind and suppress the activity of the Slug promoter, and ectopic Slug expression partially revert the KLF4-mediated phenotypes [82]. There are limited literatures about the role of KLF4 in the GI cancer EMT, but other discoveries about KLF4 regulating EMT in non-GI cancer may bring inspiration to our understanding of KLF4 in GI cancer. Researches about transcriptional regulator of KLF4 in EMT mainly concentrated on the breast cancer. In a mouse model of breast cancer, KLF4 inhibited EMT through reducing the expression of Snail, a key mediator of EMT and metastasis [81]. The expression of E-cadherin, an epithelial marker, is controlled by a balance between ZEB2 and KLF4 in cancer cell lines. KLF4 binds to the E-cadherin promoter in a region overlapping with a known ZEB2 binding site, and these two transcription factors have opposite effects on the activity of E-cadherin promoter $[84,85]$. A recent publication has shown that KLF4 was a transcriptional regulator of genes critical for EMT, and in addition, they revealed a series of key genes as direct transcriptional target of KLF4, including E-cadherin, $\mathrm{N}$-cadherin, vimentin, $\beta$-catenin, VEGF-A, endothelin-1 and Jnk1 [83]. EMT is also regulated by other factors and it is a product of crosstalk of signaling pathways. In the following sections, we will discuss the crosstalk between KLF4 and selected signaling pathways, including TGF- $\beta$, Notch, and Wnt pathways which play critical roles in EMT (Fig. 2).

\subsection{Crosstalk between KLF4 and TGF- $\beta$}

It is widely accepted that TGF- $\beta$ has a dual role during carcinogenesis. Initially it suppresses tumor formation since it inhibits cell growth and stimulates apoptosis, however, in advanced cancer TGF- $\beta$ is often overexpressed, and functions as a promoter through inducing EMT which strengthens invasiveness and metastasis [9]. TGF- $\beta$ signaling pathway is initiated though interaction between TGF- $\beta$ and a tetrameric cell surface complex of type I and type II transmembrane kinase receptors, in which type II receptor phosphorylates and activates the type I receptor. Then they phosphorylate receptor-activated Smads ( $\mathrm{Smad} 2$ and Smad3) in their C-terminals, whereafter two activated Smad proteins form complex with the common-mediator Smad4. Smad complexes translocate into the nucleus and regulate target 
gene expression in cooperation with high-affinity DNA-binding transcription factors, coactivators and co-repressors [86]. During cancer progression, TGF- $\beta$ is commonly overexpressed in various human cancers suggesting a pivotal role of TGF- $\beta$ in EMT process. TGF- $\beta /$ Smad signaling directly activates the expression of EMT transcription factors, including Snail, Slug, ZEB1, ZEB2 and Twist. Smad signaling also represses the expression of the microRNA-200 family through leading to the expression of ZEB transcription factors, afterwards, microRNA-200 family further increases the expression of ZEB at protein level and mRNA level in a feedback loop. In addition, TGF- $\beta$ also promotes the expression of MMPs such as MMP2/9, as well as components of the ECM, most likely via activation of the EMT transcription factors [87].

Emerging studies have shown that KLF4 functionally contributed to the TGF- $\beta$ induced EMT, in which the KLF4 mRNA and protein levels were found down-regulated already at first days of TGF- $\beta$ treatment. Consistent with it, depletion of KLF4 expression could remarkable accelerated the process of TGF- $\beta$ induced EMT [83]. Similar results were obtained from prostate cancer cell. In a model of TGF- $\beta$ induced prostatic EMT, Slug is the dominant regulator of EMT initiation as demonstrated through the inhibition of EMT following Slug depletion, and TGF- $\beta$-stimulated KLF4 degradation is required for Slug induction [88]. Although it is common knowledge that KLF4 is regulated through various post-translational modifications, including phosphorylation, acetylation, emerging studies suggested that KLF4 alteration could be mediated by the Ubiquitin-Proteasome System (UPS). In response to TGF- $\beta$ signaling, KLF4 is profoundly degraded through UPS, which is necessary to ensure TGF- $\beta$-induced transcriptional activation [89]. In the differentiation of vascular smooth muscle cells, KLF4 was found to transduce TGF- $\beta$ signaling via phosphorylation-mediated activation of Smad2/3 and p38MAPK pathways. KLF4 could directly bind to the TGF- $\beta$ promoter at KLF-4-binding sites 2 and 3, and recruit Smad 2 to the Smad-responsive region [90]. TGF- $\beta$ and bone morphogenetic proteins (BMPs), also belongs to TGF- $\beta$ superfamily, down-regulated KLF4 via induction of microRNA-143 and microRNA-145 in modulation of vascular smooth muscle cell phenotype [91]. Together these findings provide convincing evidence that there was a tight crosstalk between KLF4 and TGF- $\beta$ signaling pathways, and KLF4 may play a central role in tumor EMT through interaction with TGF- $\beta$ signaling.

\subsection{Crosstalk between KLF4 and Notch signaling}

Notch signaling plays a key role in the control of cell fate determination, growth and differentiation, and also plays an instrumental role in the formation and progression of multiple human tumors, including GI cancer. The canonical pathway of Notch activation involves interaction between ligands and receptors of Notch, proteolytic cleavage and translocation of intracellular domain of the notch (ICN) into the nucleus, where it associated with DNA binding protein for transcriptional activation of Notch target genes. Recent experimental evidences have suggested that Notch signaling pathway was involved in the acquisition of EMT in both physiological conditions and pathological processes, especially in the field of malignancies [92, 93], and the interaction between KLF4 and Notch may suggest the role of KLF4 in EMT process. In normal intestine development, the regulation of differentiation of goblet cells in intestine by Notch signaling at least partially mediated 
via KLF4, which is essential for the repression of intestine cells proliferation and the terminal differentiation of enterocytes [94]. In specific cell types like keratinocytes, Notch plays a central pro-differentiation and tumor suppressing function with down-regulation of the Notch1 gene being associated with cancer development. Regulatory mechanisms is that KLF4 binds to the promoter of Notch1, together with Sp3, functions as a negative modulator of Notch1 target gene transcription [95]. KLF4 is highly expressed in more than 70\% of breast cancers and functions as an oncogene, which is required for the maintenance of breast cancer stem cells. Knockdown of KLF4 inhibited migration and invasion of breast cancer cells. Further mechanistic studies revealed that the Notch signaling pathway was essential for KLF4 mediated cell migration and invasion [96]. Another research of human mammary epithelial cells suggested that KLF4 directly bound to the proximal Notch1 promoter, and siRNA-mediated suppression of KLF4 in human mammary cancer cells resulted in reduced expression of Notch1. Furthermore, the expression of KLF4 and notch1 are correlated in primary human breast tumors [96]. In intestine cancer, KLF4 is considered as a tumor suppressor gene, which is required for the terminal differentiation of goblet cells in the mouse intestine. The Notch signaling pathway suppresses goblet cell formation and is upregulated in intestinal tumors. Overexpression of Notch in HT-29 colon cancer cells reduced KLF4 levels, suppressed KLF4 promoter activity, and increased proliferation rate [97]. Taken together, interaction between KLF4 and Notch signaling may be reciprocal, which possibly be responsible for the functions of KLF4 in EMT.

\subsection{Crosstalk between KLF4 and Wnt signaling pathway}

One major signal transduction pathway which is involved in the control of pathological process in human cancer is the canonical Wnt/ $\beta$-catenin signaling. During development of human cancer, activated Wnt signaling promotes the nucleus translocation of $\beta$-catenin, leading to the consequent transcriptional activation of specific target genes via binding to the transcription factor T-cell factor/lymphocyte enhancer factor (TCF/LEF). Gene expression pattern induced by nuclear $\beta$-catenin has been found to favor tumor invasion and metastasis, and mounting evidences indicate that $\mathrm{Wnt} / \beta$-catenin signaling is involved in the process of EMT in human cancer [98, 99]. In recent years, increasing evidences supported the existence of interaction between KLF4 and Wnt signaling, which may be correlated with EMT in human carcinoma. Sellak $\mathrm{H}$ et al recently revealed that KLF4 antagonized $\beta$ catenin/TCF binding in a series of normal and cancer cells, and the inhibition was concentration-dependent. Overexpression of KLF4 in cancer cells shows a concentrationdependent reduction of TCF-luciferase as well as the ability of TCF-binding [100]. When colorectal cancer tumor suppressor adenomatous polyposis coli (APC) is inactivated by mutation, Wnt signaling is unimpeded with the nuclear accumulation of $\beta$-catenin. Christian D et al found that APC could regulate the expression of KLF4 in a colon cancer cell line through transactivating KLF4 promoter. Overexpression of KLF4 resulted in decreases in $\beta$ catenin protein and mRNA levels, and down-regulation of KLF4 lead to increase in $\beta$ catenin concentration. Their findings indicated that the suppressive effect of KLF4 may be mediated via the APC/ $\beta$-catenin signaling [101]. Zhang $\mathrm{W}$ et al also suggested that there was interaction between KLF4 and $\beta$-catenin, which played a critical role in homeostasis of the normal intestine as well as in carcinogenesis of colorectal cancers [102]. Further mechanical research revealed that KLF4 directly interacted with the C-terminal transaction domain of $\beta$ - 
catenin and inhibited $\mathrm{p} 300 / \mathrm{CBP}$ recruitment by $\beta$-catenin, additionally KLF4 also directly interacted with TCF4 independently of $\beta$-catenin, and then restrained the Wnt signaling pathway [103]. Taken together, there is a reciprocal interaction between KLF4 and Wnt signaling, which may contribute to the development of EMT in cancer.

\section{Conclusions and Future Directions}

EMT is associated with many processes of cancer development and progression, including proliferation, cell stemness, invasion and migration. Many transcription factors can trigger it, especially ZEB, Snail and Twist families. These transcription factors are downstream of signaling pathways, so in essential, EMT is a product of crosstalk between signaling pathways. KLF4, a transcription factor, functions as a tumor suppressor in GI cancers. Based on the association with main signaling pathways, including TGF- $\beta$, Wnt/ $\beta$-catenin and Notch which play critical roles in regulating EMT, the negative role of KLF4 in GI cancer EMT has been established. This review has discussed the role of KLF4 in GI cancer tumorigenesis, proliferation, differentiation, and especially EMT in summarizing what is already known, but the exact mechanism of KLF4 in cancer early initiation, cancer stem cell reprogramming and maintaining are not clear, so more work is needed to provide deeper insight into them. Recent studies have suggested that KLF4 can also function as an oncogene and is one of the four transcription factors which reprogram somatic cells into iPS. In considering such a complicated transcription factor demonstrating the molecular basis of its switch between tumor suppressor gene and oncogene should be solved urgently.

Recently, a series of studies have revealed that the functional status of p21 contributes to the switch but further studies are still needed [71].

\section{Acknowledgments}

Funding

Supported in part by grants R01-CA129956, R01-CA148954, R01CA152309 and R01CA172233 (to K.X.) from the National Institutes of Health.

\section{Abbreviations}

EMT epithelial to mesenchymal transition

KLF4 Krüppel-like factor 4

CAR adenovirus receptor

ZO-1 Zona occludin-1

TGF- $\beta \quad$ transforming growth factor- $\beta$

FGF fibroblast growth factor

STAT-3 signal transducer and activator of transcription-3

EGF epidermal growth factor

$\mathbf{N F}-\kappa \mathbf{B} \quad$ nuclear factor $-\kappa \mathrm{B}$ 


$\begin{array}{ll}\text { VEGF } & \text { vascular endothelial growth factor } \\ \text { BTE } & \text { basic transcription element } \\ \text { APC } & \text { adenomatous polyposis coli } \\ \text { IFITM3 } & \text { interferon induced transmembrane protein 3 } \\ \text { Bmi1 } & \text { B lymphoma Mo-MLV insertion region 1 } \\ \text { CDK } & \text { cyclin-dependent kinase } \\ \text { ODC } & \text { ornithine decarboxylase } \\ \text { SPRR1A } & \text { small proline-rich protein 1A } \\ \text { SPRR2A } & \text { small proline-rich protein 2A } \\ \text { KRT4 } & \text { keratin } 4 \\ \text { HDAC } & \text { histone deacetylases } \\ \text { IAP } & \text { intestinal alkaline phosphatase } \\ \text { iPS } & \text { induced pluripotent stem cells }\end{array}$

\section{References}

1. Jemal A, Bray F, Center MM, Ferlay J, Ward E, Forman D. Global cancer statistics. CA Cancer J Clin. 2011; 61(2):69-90. [PubMed: 21296855]

2. Siegel R, Naishadham D, Jemal A. Cancer statistics, 2012. CA Cancer J Clin. 2012; 62(1):10-29. [PubMed: 22237781]

3. Thompson EW, Torri J, Sabol M, Sommers CL, Byers S, Valverius EM, Martin GR, Lippman ME, Stampfer MR, Dickson RB. Oncogene-induced basement membrane invasiveness in human mammary epithelial cells. Clin Exp Metastasis. 1994; 12(3):181-194. [PubMed: 8194193]

4. Savagner P, Boyer B, Valles AM, Jouanneau J, Thiery JP. Modulations of the epithelial phenotype during embryogenesis and cancer progression. Cancer Treat Res. 1994; 71:229-249. [PubMed: 7946950]

5. Wei D, Kanai M, Huang S, Xie K. Emerging role of KLF4 in human gastrointestinal cancer. Carcinogenesis. 2006; 27(1):23-31. [PubMed: 16219632]

6. Lehembre F, Yilmaz M, Wicki A, Schomber T, Strittmatter K, Ziegler D, Kren A, Went P, Derksen PW, Berns A, et al. NCAM-induced focal adhesion assembly: a functional switch upon loss of Ecadherin. EMBO J. 2008; 27(19):2603-2615. [PubMed: 18772882]

7. Mjaatvedt $\mathrm{CH}$, Markwald RR. Induction of an epithelial-mesenchymal transition by an in vivo adheron-like complex. Dev Biol. 1989; 136(1):118-128. [PubMed: 2509260]

8. Colas E, Pedrola N, Devis L, Ertekin T, Campoy I, Martinez E, Llaurado M, Rigau M, Olivan M, Garcia M, et al. The EMT signaling pathways in endometrial carcinoma. Clin Transl Oncol. 2012; 14(10):715-720. [PubMed: 22911547]

9. Heldin CH, Vanlandewijck M, Moustakas A. Regulation of EMT by TGFbeta in cancer. FEBS Lett. 2012; 586(14):1959-1970. [PubMed: 22710176]

10. Harris TJ, Tepass U. Adherens junctions: from molecules to morphogenesis. Nat Rev Mol Cell Biol. 2010; 11(7):502-514. [PubMed: 20571587]

11. van Zijl F, Krupitza G, Mikulits W. Initial steps of metastasis: cell invasion and endothelial transmigration. Mutat Res. 2011; 728(1-2):23-34. [PubMed: 21605699] 
12. Xing X, Tang YB, Yuan G, Wang Y, Wang J, Yang Y, Chen M. The prognostic value of Ecadherin in gastric cancer: a meta-analysis. Int J Cancer. 2013; 132(11):2589-2596. [PubMed: 23169395]

13. Xu XL, Ling ZQ, Chen SZ, Li B, Ji WH, Mao WM. The impact of E-cadherin expression on the prognosis of esophageal cancer: a meta-analysis. Dis Esophagus. 2013

14. Chen X, Wang Y, Xia H, Wang Q, Jiang X, Lin Z, Ma Y, Yang Y, Hu M. Loss of E-cadherin promotes the growth, invasion and drug resistance of colorectal cancer cells and is associated with liver metastasis. Mol Biol Rep. 2012; 39(6):6707-6714. [PubMed: 22311018]

15. Puhalla H, Herberger B, Soleiman A, Filipits M, Laengle F, Gruenberger T, Wrba F. E-cadherin and beta-catenin expression in normal, inflamed and cancerous gallbladder tissue. Anticancer Res. 2005; 25(6B):4249-4254. [PubMed: 16309224]

16. Jiang XM, Zhang JB, Xiong J, Huang XX, Ren ZG. Altered Distribution and Expression Pattern of E-cadherin in Hepatocellular Carcinomas: Correlations with Prognosis and Clinical Features. Asian Pac J Cancer Prev. 2012; 13(12):6455-6461. [PubMed: 23464474]

17. Karayiannakis AJ, Syrigos KN, Chatzigianni E, Papanikolaou S, Alexiou D, Kalahanis N, Rosenberg T, Bastounis E. Aberrant E-cadherin expression associated with loss of differentiation and advanced stage in human pancreatic cancer. Anticancer Res. 1998; 18(6A):4177-4180. [PubMed: 9891464]

18. Derycke LD, Bracke ME. N-cadherin in the spotlight of cell-cell adhesion, differentiation, embryogenesis, invasion and signalling. Int J Dev Biol. 2004; 48(5-6):463-476. [PubMed: 15349821]

19. Huang C, Qiu Z, Wang L, Peng Z, Jia Z, Logsdon CD, Le X, Wei D, Huang S, Xie K. A novel FoxM1-caveolin signaling pathway promotes pancreatic cancer invasion and metastasis. Cancer Res. 2012; 72(3):655-665. [PubMed: 22194465]

20. Christofori G. New signals from the invasive front. Nature. 2006; 441(7092):444-450. [PubMed: 16724056]

21. Thiery JP, Acloque H, Huang RY, Nieto MA. Epithelial-mesenchymal transitions in development and disease. Cell. 2009; 139(5):871-890. [PubMed: 19945376]

22. Yang J, Weinberg RA. Epithelial-mesenchymal transition: at the crossroads of development and tumor metastasis. Dev Cell. 2008; 14(6):818-829. [PubMed: 18539112]

23. Rathinam R, Berrier A, Alahari SK. Role of Rho GTPases and their regulators in cancer progression. Front Biosci. 2011; 16:2561-2571.

24. Bieker JJ. Kruppel-like factors: three fingers in many pies. J Biol Chem. 2001; 276(37):3435534358. [PubMed: 11443140]

25. Philipsen S, Suske G. A tale of three fingers: the family of mammalian Sp/XKLF transcription factors. Nucleic Acids Res. 1999; 27(15):2991-3000. [PubMed: 10454592]

26. Suske G, Bruford E, Philipsen S. Mammalian SP/KLF transcription factors: bring in the family. Genomics. 2005; 85(5):551-556. [PubMed: 15820306]

27. Shields JM, Christy RJ, Yang VW. Identification and characterization of a gene encoding a gutenriched Kruppel-like factor expressed during growth arrest. J Biol Chem. 1996; 271(33):20009_ 20017. [PubMed: 8702718]

28. Garrett-Sinha LA, Eberspaecher H, Seldin MF, de Crombrugghe B. A gene for a novel zinc-finger protein expressed in differentiated epithelial cells and transiently in certain mesenchymal cells. $\mathrm{J}$ Biol Chem. 1996; 271(49):31384-31390. [PubMed: 8940147]

29. Yet SF, McA'Nulty MM, Folta SC, Yen HW, Yoshizumi M, Hsieh CM, Layne MD, Chin MT, Wang H, Perrella MA, et al. Human EZF, a Kruppel-like zinc finger protein, is expressed in vascular endothelial cells and contains transcriptional activation and repression domains. J Biol Chem. 1998; 273(2):1026-1031. [PubMed: 9422764]

30. Shields JM, Yang VW. Identification of the DNA sequence that interacts with the gut-enriched Kruppel-like factor. Nucleic Acids Res. 1998; 26(3):796-802. [PubMed: 9443972]

31. Yanagida A, Sogawa K, Yasumoto KI, Fujii-Kuriyama Y. A novel cis-acting DNA element required for a high level of inducible expression of the rat P-450c gene. Mol Cell Biol. 1990; 10(4):1470-1475. [PubMed: 2320004] 
32. Yang Y, Goldstein BG, Chao HH, Katz JP. KLF4 and KLF5 regulate proliferation, apoptosis and invasion in esophageal cancer cells. Cancer Biol Ther. 2005; 4(11):1216-1221. [PubMed: 16357509]

33. Wang N, Liu ZH, Ding F, Wang XQ, Zhou CN, Wu M. Down-regulation of gut-enriched Kruppellike factor expression in esophageal cancer. World J Gastroenterol. 2002; 8(6):966-970. [PubMed: 12439907]

34. Luo A, Kong J, Hu G, Liew CC, Xiong M, Wang X, Ji J, Wang T, Zhi H, Wu M, et al. Discovery of $\mathrm{Ca} 2+-$ relevant and differentiation-associated genes downregulated in esophageal squamous cell carcinoma using cDNA microarray. Oncogene. 2004; 23(6):1291-1299. [PubMed: 14647409]

35. Wei D, Gong W, Kanai M, Schlunk C, Wang L, Yao JC, Wu TT, Huang S, Xie K. Drastic downregulation of Kruppel-like factor 4 expression is critical in human gastric cancer development and progression. Cancer Res. 2005; 65(7):2746-2754. [PubMed: 15805274]

36. Zhang N, Zhang J, Wang ZW, Zha L, Huang Z. Altered expression of Kruppel-like factor 4 and beta-catenin in human gastric cancer. Oncol Lett. 2012; 3(5):1017-1022. [PubMed: 22783383]

37. Dang DT, Bachman KE, Mahatan CS, Dang LH, Giardiello FM, Yang VW. Decreased expression of the gut-enriched Kruppel-like factor gene in intestinal adenomas of multiple intestinal neoplasia mice and in colonic adenomas of familial adenomatous polyposis patients. FEBS Lett. 2000; 476(3):203-207. [PubMed: 10913614]

38. Choi BJ, Cho YG, Song JW, Kim CJ, Kim SY, Nam SW, Yoo NJ, Lee JY, Park WS. Altered expression of the KLF4 in colorectal cancers. Pathol Res Pract. 2006; 202(8):585-589. [PubMed: 16814484]

39. Patel NV, Ghaleb AM, Nandan MO, Yang VW. Expression of the tumor suppressor Kruppel-like factor 4 as a prognostic predictor for colon cancer. Cancer Epidemiol Biomarkers Prev. 2010; 19(10):2631-2638. [PubMed: 20699379]

40. Li Q, Gao Y, Jia Z, Mishra L, Guo K, Li Z, Le X, Wei D, Huang S, Xie K. Dysregulated Kruppellike factor 4 and vitamin $\mathrm{D}$ receptor signaling contribute to progression of hepatocellular carcinoma. Gastroenterology. 2012; 143(3):799-810. e791-792. [PubMed: 22677193]

41. Zhang W, Geiman DE, Shields JM, Dang DT, Mahatan CS, Kaestner KH, Biggs JR, Kraft AS, Yang VW. The gut-enriched Kruppel-like factor (Kruppel-like factor 4) mediates the transactivating effect of p53 on the p21WAF1/Cip1 promoter. J Biol Chem. 2000; 275(24):1839118398. [PubMed: 10749849]

42. Ton-That H, Kaestner KH, Shields JM, Mahatanankoon CS, Yang VW. Expression of the gutenriched Kruppel-like factor gene during development and intestinal tumorigenesis. FEBS Lett. 1997; 419(2-3):239-243. [PubMed: 9428642]

43. Dang DT, Chen X, Feng J, Torbenson M, Dang LH, Yang VW. Overexpression of Kruppel-like factor 4 in the human colon cancer cell line RKO leads to reduced tumorigenecity. Oncogene. 2003; 22(22):3424-3430. [PubMed: 12776194]

44. Li Q, Jia Z, Wang L, Kong X, Guo K, Tan D, Le X, Wei D, Huang S, Mishra L, et al. Disruption of Klf4 in villin-positive gastric progenitor cells promotes formation and progression of tumors of the antrum in mice. Gastroenterology. 2012; 142(3):531-542. [PubMed: 22155367]

45. Koo CY, Muir KW, Lam EW. FOXM1: From cancer initiation to progression and treatment. Biochim Biophys Acta. 2012; 1819(1):28-37. [PubMed: 21978825]

46. Kong X, Li L, Li Z, Le X, Huang C, Jia Z, Cui J, Huang S, Wang L, Xie K. Dysregulated expression of FOXM1 isoforms drive progression of pancreatic cancer. Cancer Res. 2013

47. Katz JP, Perreault N, Goldstein BG, Actman L, McNally SR, Silberg DG, Furth EE, Kaestner KH. Loss of Klf4 in mice causes altered proliferation and differentiation and precancerous changes in the adult stomach. Gastroenterology. 2005; 128(4):935-945. [PubMed: 15825076]

48. Katz JP, Perreault N, Goldstein BG, Lee CS, Labosky PA, Yang VW, Kaestner KH. The zincfinger transcription factor Klf4 is required for terminal differentiation of goblet cells in the colon. Development. 2002; 129(11):2619-2628. [PubMed: 12015290]

49. Ghaleb AM, McConnell BB, Nandan MO, Katz JP, Kaestner KH, Yang VW. Haploinsufficiency of Kruppel-like factor 4 promotes adenomatous polyposis coli dependent intestinal tumorigenesis. Cancer Res. 2007; 67(15):7147-7154. [PubMed: 17671182] 
50. Tian Y, Luo A, Cai Y, Su Q, Ding F, Chen H, Liu Z. MicroRNA-10b promotes migration and invasion through KLF4 in human esophageal cancer cell lines. J Biol Chem. 2010; 285(11):79867994. [PubMed: 20075075]

51. Dang DT, Mahatan CS, Dang LH, Agboola IA, Yang VW. Expression of the gut-enriched Kruppel-like factor (Kruppel-like factor 4) gene in the human colon cancer cell line RKO is dependent on CDX2. Oncogene. 2001; 20(35):4884-4890. [PubMed: 11521200]

52. Zhao W, Hisamuddin IM, Nandan MO, Babbin BA, Lamb NE, Yang VW. Identification of Kruppel-like factor 4 as a potential tumor suppressor gene in colorectal cancer. Oncogene. 2004; 23(2):395-402. [PubMed: 14724568]

53. Chen ZY, Wang X, Zhou Y, Offner G, Tseng CC. Destabilization of Kruppel-like factor 4 protein in response to serum stimulation involves the ubiquitin-proteasome pathway. Cancer Res. 2005; 65(22):10394-10400. [PubMed: 16288030]

54. Zhang G, Zhu H, Wang Y, Yang S, Liu M, Zhang W, Quan L, Bai J, Liu Z, Xu N. Kruppel-like factor 4 represses transcription of the survivin gene in esophageal cancer cell lines. Biol Chem. 2009; 390(5-6):463-469. [PubMed: 19361279]

55. Li D, Peng Z, Tang H, Wei P, Kong X, Yan D, Huang F, Li Q, Le X, Xie K. KLF4-mediated negative regulation of IFITM3 expression plays a critical role in colon cancer pathogenesis. Clin Cancer Res. 2011; 17(11):3558-3568. [PubMed: 21531817]

56. Yu T, Chen X, Zhang W, Colon D, Shi J, Napier D, Rychahou P, Lu W, Lee EY, Weiss HL, et al. Regulation of the potential marker for intestinal cells, Bmi1, by beta-catenin and the zinc finger protein KLF4: implications for colon cancer. J Biol Chem. 2012; 287(6):3760-3768. [PubMed: 22170051]

57. Chen X, Johns DC, Geiman DE, Marban E, Dang DT, Hamlin G, Sun R, Yang VW. Kruppel-like factor 4 (gut-enriched Kruppel-like factor) inhibits cell proliferation by blocking G1/S progression of the cell cycle. J Biol Chem. 2001; 276(32):30423-30428. [PubMed: 11390382]

58. Yoon HS, Chen X, Yang VW. Kruppel-like factor 4 mediates p53-dependent G1/S cell cycle arrest in response to DNA damage. J Biol Chem. 2003; 278(4):2101-2105. [PubMed: 12427745]

59. Yoon HS, Yang VW. Requirement of Kruppel-like factor 4 in preventing entry into mitosis following DNA damage. J Biol Chem. 2004; 279(6):5035-5041. [PubMed: 14627709]

60. Malumbres M, Barbacid M. Cell cycle, CDKs and cancer: a changing paradigm. Nat Rev Cancer. 2009; 9(3):153-166. [PubMed: 19238148]

61. Nickenig G, Baudler S, Muller C, Werner C, Werner N, Welzel H, Strehlow K, Bohm M. Redoxsensitive vascular smooth muscle cell proliferation is mediated by GKLF and Id3 in vitro and in vivo. FASEB J. 2002; 16(9):1077-1086. [PubMed: 12087069]

62. Traka MH, Chambers KF, Lund EK, Goodlad RA, Johnson IT, Mithen RF. Involvement of KLF4 in sulforaphane- and iberin-mediated induction of p21(waf1/cip1). Nutr Cancer. 2009; 61(1):137145. [PubMed: 19116884]

63. Wei D, Kanai M, Jia Z, Le X, Xie K. Kruppel-like factor 4 induces p27Kip1 expression in and suppresses the growth and metastasis of human pancreatic cancer cells. Cancer Res. 2008; 68(12): 4631-4639. [PubMed: 18559508]

64. Wei D, Wang L, Kanai M, Jia Z, Le X, Li Q, Wang H, Xie K. KLF4alpha up-regulation promotes cell cycle progression and reduces survival time of patients with pancreatic cancer. Gastroenterology. 2010; 139(6):2135-2145. [PubMed: 20727893]

65. Shie JL, Chen ZY, Fu M, Pestell RG, Tseng CC. Gut-enriched Kruppel-like factor represses cyclin D1 promoter activity through Sp1 motif. Nucleic Acids Res. 2000; 28(15):2969-2976. [PubMed: 10908361]

66. Chen ZY, Shie JL, Tseng CC. Gut-enriched Kruppel-like factor represses ornithine decarboxylase gene expression and functions as checkpoint regulator in colonic cancer cells. J Biol Chem. 2002; 277(48):46831-46839. [PubMed: 12297499]

67. Yoon HS, Ghaleb AM, Nandan MO, Hisamuddin IM, Dalton WB, Yang VW. Kruppel-like factor 4 prevents centrosome amplification following gamma-irradiation-induced DNA damage. Oncogene. 2005; 24(25):4017-4025. [PubMed: 15806166]

68. Foster KW, Ren S, Louro ID, Lobo-Ruppert SM, McKie-Bell P, Grizzle W, Hayes MR, Broker TR, Chow LT, Ruppert JM. Oncogene expression cloning by retroviral transduction of adenovirus 
E1A-immortalized rat kidney RK3E cells: transformation of a host with epithelial features by cMYC and the zinc finger protein GKLF. Cell Growth Differ. 1999; 10(6):423-434. [PubMed: 10392904]

69. Foster KW, Frost AR, McKie-Bell P, Lin CY, Engler JA, Grizzle WE, Ruppert JM. Increase of GKLF messenger RNA and protein expression during progression of breast cancer. Cancer Res. 2000; 60(22):6488-6495. [PubMed: 11103818]

70. Pandya AY, Talley LI, Frost AR, Fitzgerald TJ, Trivedi V, Chakravarthy M, Chhieng DC, Grizzle WE, Engler JA, Krontiras H, et al. Nuclear localization of KLF4 is associated with an aggressive phenotype in early-stage breast cancer. Clin Cancer Res. 2004; 10(8):2709-2719. [PubMed: 15102675]

71. Rowland BD, Peeper DS. KLF4, p21 and context-dependent opposing forces in cancer. Nat Rev Cancer. 2006; 6(1):11-23. [PubMed: 16372018]

72. Segre JA, Bauer C, Fuchs E. Klf4 is a transcription factor required for establishing the barrier function of the skin. Nat Genet. 1999; 22(4):356-360. [PubMed: 10431239]

73. Chen X, Whitney EM, Gao SY, Yang VW. Transcriptional profiling of Kruppel-like factor 4 reveals a function in cell cycle regulation and epithelial differentiation. J Mol Biol. 2003; 326(3): 665-677. [PubMed: 12581631]

74. Jenkins TD, Opitz OG, Okano J, Rustgi AK. Transactivation of the human keratin 4 and EpsteinBarr virus ED-L2 promoters by gut-enriched Kruppel-like factor. J Biol Chem. 1998; 273(17): 10747-10754. [PubMed: 9553140]

75. Brembeck FH, Rustgi AK. The tissue-dependent keratin 19 gene transcription is regulated by GKLF/KLF4 and Sp1. J Biol Chem. 2000; 275(36):28230-28239. [PubMed: 10859317]

76. Hinnebusch BF, Siddique A, Henderson JW, Malo MS, Zhang W, Athaide CP, Abedrapo MA, Chen X, Yang VW, Hodin RA. Enterocyte differentiation marker intestinal alkaline phosphatase is a target gene of the gut-enriched Kruppel-like factor. Am J Physiol Gastrointest Liver Physiol. 2004; 286(1):G23-30. [PubMed: 12919939]

77. Flandez M, Guilmeau S, Blache P, Augenlicht LH. KLF4 regulation in intestinal epithelial cell maturation. Exp Cell Res. 2008; 314(20):3712-3723. [PubMed: 18977346]

78. Okita K, Yamanaka S. Induced pluripotent stem cells: opportunities and challenges. Philos Trans R Soc Lond B Biol Sci. 2011; 366(1575):2198-2207. [PubMed: 21727125]

79. Leng Z, Tao K, Xia Q, Tan J, Yue Z, Chen J, Xi H, Li J, Zheng H. Kruppel-like factor 4 acts as an oncogene in colon cancer stem cell-enriched spheroid cells. PLoS One. 2013; 8(2):e56082. [PubMed: 23418515]

80. De Craene B, Berx G. Regulatory networks defining EMT during cancer initiation and progression. Nat Rev Cancer. 2013; 13(2):97-110. [PubMed: 23344542]

81. Yori JL, Seachrist DD, Johnson E, Lozada KL, Abdul-Karim FW, Chodosh LA, Schiemann WP, Keri RA. Kruppel-like factor 4 inhibits tumorigenic progression and metastasis in a mouse model of breast cancer. Neoplasia. 2011; 13(7):601-610. [PubMed: 21750654]

82. Lin ZS, Chu HC, Yen YC, Lewis BC, Chen YW. Kruppel-like factor 4, a tumor suppressor in hepatocellular carcinoma cells reverts epithelial mesenchymal transition by suppressing slug expression. PLoS One. 2012; 7(8):e43593. [PubMed: 22937066]

83. Tiwari N, Meyer-Schaller N, Arnold P, Antoniadis H, Pachkov M, van Nimwegen E, Christofori G. Klf4 is a transcriptional regulator of genes critical for EMT, including Jnk1 (Mapk8). PLoS One. 2013; 8(2):e57329. [PubMed: 23451207]

84. Koopmansch B, Berx G, Foidart JM, Gilles C, Winkler R. Interplay between KLF4 and ZEB2/ SIP1 in the regulation of E-cadherin expression. Biochem Biophys Res Commun. 2013; 431(4): 652-657. [PubMed: 23376074]

85. Li R, Liang J, Ni S, Zhou T, Qing X, Li H, He W, Chen J, Li F, Zhuang Q, et al. A mesenchymalto-epithelial transition initiates and is required for the nuclear reprogramming of mouse fibroblasts. Cell Stem Cell. 2010; 7(1):51-63. [PubMed: 20621050]

86. Shi Y, Massague J. Mechanisms of TGF-beta signaling from cell membrane to the nucleus. Cell. 2003; 113(6):685-700. [PubMed: 12809600]

87. Katsuno Y, Lamouille S, Derynck R. TGF-beta signaling and epithelial-mesenchymal transition in cancer progression. Curr Opin Oncol. 2013; 25(1):76-84. [PubMed: 23197193] 
88. Liu YN, Abou-Kheir W, Yin JJ, Fang L, Hynes P, Casey O, Hu D, Wan Y, Seng V, SheppardTillman $\mathrm{H}$, et al. Critical and reciprocal regulation of KLF4 and SLUG in transforming growth factor beta-initiated prostate cancer epithelial-mesenchymal transition. Mol Cell Biol. 2012; 32(5): 941-953. [PubMed: 22203039]

89. Hu D, Wan Y. Regulation of Kruppel-like factor 4 by the anaphase promoting complex pathway is involved in TGF-beta signaling. J Biol Chem. 2011; 286(9):6890-6901. [PubMed: 21177849]

90. Li HX, Han M, Bernier M, Zheng B, Sun SG, Su M, Zhang R, Fu JR, Wen JK. Kruppel-like factor 4 promotes differentiation by transforming growth factor-beta receptor-mediated Smad and p38 MAPK signaling in vascular smooth muscle cells. J Biol Chem. 2010; 285(23):17846-17856. [PubMed: 20375011]

91. Davis-Dusenbery BN, Chan MC, Reno KE, Weisman AS, Layne MD, Lagna G, Hata A. downregulation of Kruppel-like factor-4 (KLF4) by microRNA-143/145 is critical for modulation of vascular smooth muscle cell phenotype by transforming growth factor-beta and bone morphogenetic protein 4. J Biol Chem. 2011; 286(32):28097-28110. [PubMed: 21673106]

92. Wang Z, Li Y, Kong D, Sarkar FH. The role of Notch signaling pathway in epithelialmesenchymal transition (EMT) during development and tumor aggressiveness. Curr Drug Targets. 2010; 11(6):745-751. [PubMed: 20041844]

93. Timmerman LA, Grego-Bessa J, Raya A, Bertran E, Perez-Pomares JM, Diez J, Aranda S, Palomo S, McCormick F, Izpisua-Belmonte JC, et al. Notch promotes epithelial-mesenchymal transition during cardiac development and oncogenic transformation. Genes Dev. 2004; 18(1):99-115. [PubMed: 14701881]

94. Li IC, Chan CT, Lu YF, Wu YT, Chen YC, Li GB, Lin CY, Hwang SP. Zebrafish kruppel-like factor 4a represses intestinal cell proliferation and promotes differentiation of intestinal cell lineages. PLoS One. 2011; 6(6):e20974. [PubMed: 21687630]

95. Lambertini C, Pantano S, Dotto GP. Differential control of Notch1 gene transcription by Klf4 and Sp3 transcription factors in normal versus cancer-derived keratinocytes. PLoS One. 2010; 5(4):e10369. [PubMed: 20442780]

96. Liu Z, Teng L, Bailey SK, Frost AR, Bland KI, LoBuglio AF, Ruppert JM, Lobo-Ruppert SM. Epithelial transformation by KLF4 requires Notch1 but not canonical Notch1 signaling. Cancer Biol Ther. 2009; 8(19):1840-1851. [PubMed: 19717984]

97. Ghaleb AM, Aggarwal G, Bialkowska AB, Nandan MO, Yang VW. Notch inhibits expression of the Kruppel-like factor 4 tumor suppressor in the intestinal epithelium. Mol Cancer Res. 2008; 6(12):1920-1927. [PubMed: 19074836]

98. Sarkar FH, Li Y, Wang Z, Kong D. The role of nutraceuticals in the regulation of Wnt and Hedgehog signaling in cancer. Cancer Metastasis Rev. 2010; 29(3):383-394. [PubMed: 20711635]

99. Schmalhofer O, Brabletz S, Brabletz T. E-cadherin, beta-catenin, and ZEB1 in malignant progression of cancer. Cancer Metastasis Rev. 2009; 28(1-2):151-166. [PubMed: 19153669]

100. Sellak H, Wu S, Lincoln TM. KLF4 and SOX9 transcription factors antagonize beta-catenin and inhibit TCF-activity in cancer cells. Biochim Biophys Acta. 2012; 1823(10):1666-1675. [PubMed: 22766303]

101. Stone CD, Chen ZY, Tseng CC. Gut-enriched Kruppel-like factor regulates colonic cell growth through APC/beta-catenin pathway. FEBS Lett. 2002; 530(1-3):147-152. [PubMed: 12387883]

102. Zhang W, Chen X, Kato Y, Evans PM, Yuan S, Yang J, Rychahou PG, Yang VW, He X, Evers $\mathrm{BM}$, et al. Novel cross talk of Kruppel-like factor 4 and beta-catenin regulates normal intestinal homeostasis and tumor repression. Mol Cell Biol. 2006; 26(6):2055-2064. [PubMed: 16507986]

103. Evans PM, Chen X, Zhang W, Liu C. KLF4 interacts with beta-catenin/TCF4 and blocks p300/CBP recruitment by beta-catenin. Mol Cell Biol. 2010; 30(2):372-381. [PubMed: 19901072] 


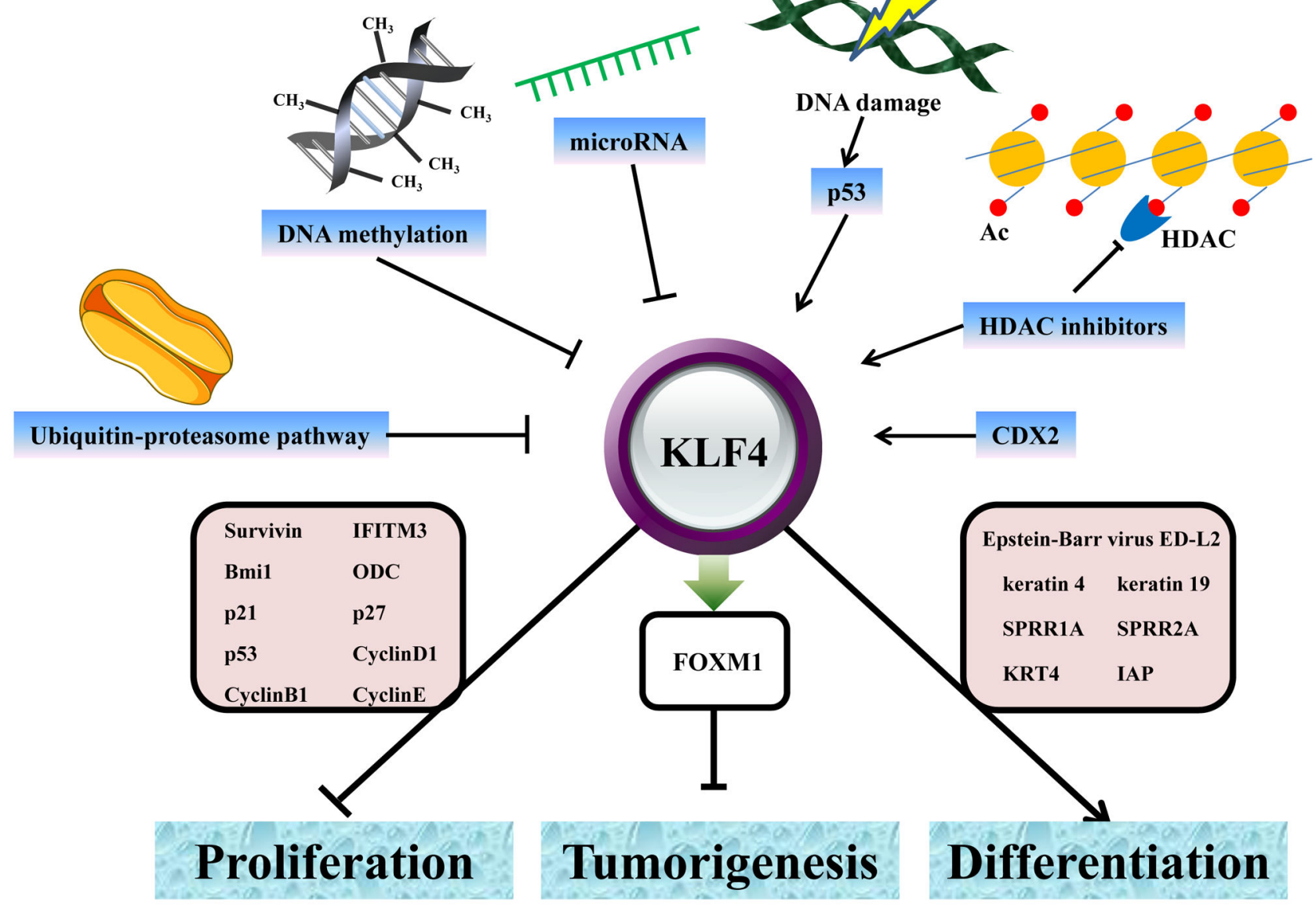

Fig. 1. The Suppressor Role of KLF4 in GI Cancer

The expression of KLF4 is inhibited by DNA methylation, microRNA and ubiquitinproteasome pathway. In the case of DNA damage, p53 induces the expression of KLF4, and KLF4 can also be upregulated by HDAC inhibitors and CDX2. Overexpression of KLF4 leads to altered expression of a series of its downstream target genes which mediate the suppressor role of KLF4 in GI cancer tumorigenesis and proliferation, and the promoter role in cancer differentiation. 


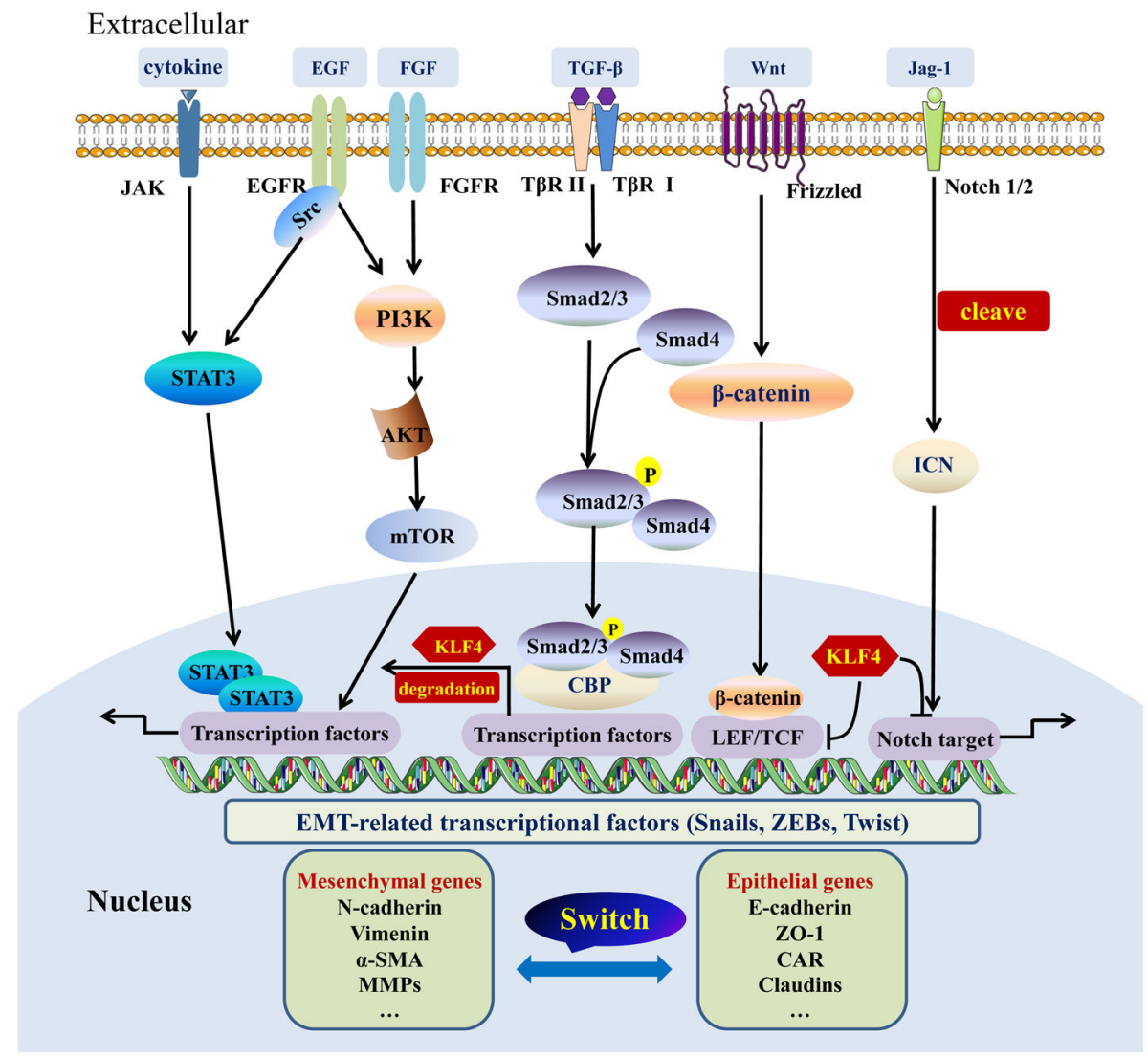

Fig. 2. The functions of KLF4 involved in the mechanism of EMT

EMT is a product of crosstalk between signaling pathways, including TGF- $\beta$, Wnt $/ \beta$-catenin, Notch, FGF, STAT3 and EGF. By regulating the transcription factors (ZEBs, Snails and Twist), these signaling pathways switch the epithelial phenotype to mesenchymal phenotype. In cancer cells, KLF4 represses the EMT through interacting with TGF- $\beta$, Notch and Wnt/ $\beta$-catenin signaling pathways. The degradation of KLF4 through UPS is necessary to TGF- $\beta$ induced transcriptional activation. In Notch signaling pathway, KLF4 negatively regulates the expression of Notch1 and functions as a negative modulator of Notch1 target genes' transcription. KLF4 also interacts with Wnt/ $\beta$-catenin by antagonizing the binding of $\beta$-catenin to TCF and represses the transcriptional activity of TCF. 